\title{
Experimental and Computational Approaches to the Molecular Structure of 3-(2-Mercaptopyridine)phthalonitrile
}

\author{
Hasan Tanak, ${ }^{\dagger}$ Yavuz Köysal, ${ }^{\dagger}$ Şamil Işık,,${ }^{\ddagger}$ Hanifi Yaman, ${ }^{\S}$ and Vefa Ahsen ${ }^{\S}$ \\ Department of Physics, Faculty of Arts and Sciences, Amasya University, 05100, Amasya, Turkey \\ ${ }^{*} E$-mail: hasantanak@gmail.com \\ ${ }^{\dagger}$ Samsun Vocational School, Ondokuz Mayls University, 55139, Kurupelit, Samsun, Turkey \\ ${ }^{\ddagger}$ Department of Physics, Faculty of Arts and Sciences, Ondokuz Mayls University, 55139, Kurupelit, Samsun, Turkey \\ ${ }^{\S}$ Gebze Institute of Technology Department of Chemistry P.O. Box 141, Gebze-Kocaeli, 41400, Turkey \\ Received October 5, 2010, Accepted December 21, 2010
}

\begin{abstract}
The compound 3-(2-Mercaptopyridine)phthalonitrile has been synthesized and characterized by IR, UV-vis, and $\mathrm{X}$-ray single-crystal determination. The molecular geometry from X-ray determination of the title compound in the ground state has been compared using the Hartree-Fock (HF) and density functional theory (DFT) with the 6-31G(d) basis set. The calculated results show that the DFT and HF can well reproduce the structure of the title compound. The energetic behavior of the title compound in solvent media was examined using the B3LYP method with the 6-31G(d) basis set by applying the Onsager and polarizable continuum model. Using the TD-DFT and TD-HF methods, electronic absorption spectra of the title compound have been predicted and good agreement with the TD-DFT method and the experimental determination was found. The predicted nonlinear optical properties of the title compound are much greater than those of urea. Besides, molecular electrostatic potential of the title compound were investigated by theoretical calculations. The thermodynamic properties of the compound at different temperatures have been calculated and corresponding relations between the properties and temperature have also been obtained.
\end{abstract}

Key Words: X-ray structure, Solvent effects, Molecular electrostatic potential (MEP), DFT, NLO

\section{Introduction}

Organosulfur compounds are well recognized in chemical and biological processes. ${ }^{1,2}$ Neutral pyridine-2-thione is a simple prototype sulfur-containing analogue of purine and pyrimidine nucleobases. It binds metal ions in different bonding modes. ${ }^{3-5}$ The versatility of pyridine-2-thione is attributed to the size of S-atoms and its proximity to pyridyl-N. The large size of the $\mathrm{S}$ atoms makes it easier to adopt different angles when it is bonded with metal ion in the complex. This has incorporated researchers to find out critically the chemistry of pyridine2-thione.

Phthalonitrile derivatives are known precursors to phthalocyanines, an important class of molecules with various application possibilities in sensors, catalysis, non-linear optics (NLO), optical data storage, photodynamic cancer therapy and nanotechnology. ${ }^{6,7}$ Vibrational studies of these precursor molecules are of interest in their own right and they are extremely valuable when performing vibrational studies of larger composite molecular systems. ${ }^{8}$

NLO materials have been attractive in recent years with respect to their future potential applications in the field of optoelectronic such as optical communication, optical computing, optical switching, and dynamic image processing. ${ }^{9,10}$ Due to their high molecular hyperpolarizabilities, organic materials display a number of significant non-linear optical properties. NLO materials were categorized as multilayered semi-conductor structures, molecular based macroscopic assemblies, and traditional inorganic solids. A variety of organic, inorganic and organometallic molecular systems have been studied for NLO activity. $^{10,11}$

By means of increasing development of computational chemistry in the past decade, the research of theoretical modeling of drug design, functional material design, etc., has become much more mature than ever. Many important chemical and physical properties of biological and chemical systems can be predicted from the first principles by various computational techniques. ${ }^{12,13}$ In recent years, density functional theory (DFT) has been a shooting star in theoretical modeling. The development of better and better exchange-correlation functionals made it possible to calculate many molecular properties with comparable accuracies to traditional correlated $a b$ initio methods, with more favorable computational costs. ${ }^{14}$ Literature survey revealed that the DFT has a great accuracy in reproducing the experimental values of in geometry, dipol moment, vibrational frequency, etc. ${ }^{15-19}$

In this paper, we report the synthesis, characterization and crystal structure of the compound 3-(2-Mercaptopyridine)phthalonitrile as well as the theoretical studies on it by using the HF/6-31G(d) and DFT/B3LYP/6-31G(d) methods. The properties of the structural geometry, molecular electrostatic potential (MEP), thermodynamic properties and nonlinear optical properties for the title compound at the B3LYP/6-31G(d) level were studied. These calculations are valuable for providing insight into molecular properties of pyridine and phthalonitrile compounds.

\section{Experimental and Theoretical Methods}

Physical Measurements. The IR spectra were recorded in the $4000-400 \mathrm{~cm}^{-1}$ region using $\mathrm{KBr}$ pellets on a Bio-Rad FTS 
175C FT-IR spectrophotometer. Electronic absorption spectra were measured on a Shimadzu $2001 \mathrm{UV}$-vis spectrophotometer in chloroform.

Synthesis. 3-(2-Mercaptopyridine)phthalonitrile compound was synthesized, purified and characterized according to literature procedure. ${ }^{20}$ The synthesis of the 3-(2-Mercaptopyridine) phthalonitrile is given in Scheme 1.

Crystal Structure Determination. The molecular data were collected on an Stoe IPDS II $^{21}$ diffractometer using the Mo K $\alpha$ radiation at room temperature. For the title compound data colleciton: X-AREA; ${ }^{21}$ cell refinement: X-AREA; data reduction: $\mathrm{X}$-RED $32{ }^{21}{ }^{21}$ program used to solve structure: SHELXS97; ${ }^{22}$ program used to refine structure: SHELXL97; ${ }^{22}$ molecular figures: ORTEP- $3 ;^{23}$ publication software: WinGX ${ }^{24}$ and PARST. ${ }^{25}$ The structure was solved by direct methods with SHELXS-97 and refined by full-matrix least-squares procedures on $F^{2}$, using the program SHELXL-97 computer program belonging to the WinGX software package. All non-hydrogen atoms were refined anisotropically. All hydrogen atom positions were refined using a riding model. Because the intensity data collected for the title structure are generally weak, $\mathrm{R}_{\text {int }}$ appeared to be slightly larger. Details of the data collection conditions and the parameters of refinement process are given in Supplementary Table 1.

Computational Methods. The molecular geometry was taken directly from the X-ray diffraction experimental result without any constraints. In the next step, the DFT calculations with a hybrid functional B3LYP (Becke's three parameter hybrid functional using the LYP correlation functional) with the 6-31G(d) basis set and Hatree-Fock calculations with the 6-31G(d) basis set using the Berny method ${ }^{26,27}$ were performed with the Gaussian $03 \mathrm{~W}$ software package. ${ }^{28}$ The harmonic vibrational frequencies were calculated at the same level of theory for the optimized structures and the obtained frequencies were scaled by 0.9613 and $0.8929 .^{29}$ Vibrational band assignments were made using the Gauss-View molecular visualisation program. ${ }^{30}$ The electronic absorption spectra were calculated using the time-dependent density functional theory (TD-DFT) and Hartree-Fock (TD-HF) methods. ${ }^{31-34}$ In addition, the electronic absorption spectra were calculated in chloroform solution using the Polarizable Continuum Model (PCM) method. ${ }^{35-37}$ In order to evaluate the total energy and dipole moment behavior of the title compound in solvent media, we also carried out optimization calculations in three solvents (chloroform, ethanol and water) at the B3LYP/6-31G(d) level using the Onsager ${ }^{38}$ and PCM methods. To investigate the reactive sites of the title compound the molecular electrostatic potential was evaluated using<smiles>N#Cc1cccc([N+](=O)[O-])c1C#N</smiles><smiles>COc1ccccn1</smiles><smiles>N#Cc1cccc(Sc2ccccn2)c1C#N</smiles>

Scheme 1. Synthesis of the title compound $\mathrm{C}_{13} \mathrm{H}_{7} \mathrm{~N}_{3} \mathrm{~S}$ the B3LYP/6-31G(d) method. The molecular electrostatic potential, $\mathrm{V}(\mathbf{r})$, at a given point $r(x, y, z)$ in the vicinity of the molecule is defined in terms of the interaction energy between the electrical charge generated by the molecule's electrons and nuclei and a positive test charge (a proton) located at $\mathbf{r}$. For the system studied the $\mathrm{V}(\mathbf{r})$ values were calculated as described previously using the equation ${ }^{39}$

$$
\mathrm{V}(\mathbf{r})=\sum_{\mathrm{A}} \frac{\mathrm{Z}_{\mathrm{A}}}{\left|\mathbf{R}_{\mathrm{A}}-\mathbf{r}\right|}-\int \frac{\rho\left(\mathbf{r}^{\prime}\right)}{\left|\mathbf{r}^{\prime}-\mathbf{r}\right|} \mathrm{d} \mathbf{r}^{\prime}
$$

where $Z_{A}$ is the charge of nucleus $A$, located at $\mathbf{R}_{\mathbf{A}}, \rho\left(\mathbf{r}^{\prime}\right)$ is the electronic density function of the molecule, and $\mathbf{r}^{\prime}$ is the dummy integration variable. The mean linear polarizability and mean first hyperpolarizability properties of the title compound were obtained by molecular polarizabilities based on theoretical calculations. The thermodynamic properties of the title compound at different temperatures were calculated on the basis of vibrational analyses.

\section{Results and Discussions}

Description of the Crystal Structure. The title compound, an Ortep-3 view of which is shown in Fig. 1, crystallizes in the triclinic space group $P \overline{1}$ with two molecules in the unit cell. The asymmetric unit in the crystal structure contains only one molecule. In the title compound, the molecular structure is not planar. The dihedral angle between $\mathrm{C} 1-\mathrm{N} 11$ and $\mathrm{C} 7-\mathrm{C} 12$ rings is $62.11(1)^{\circ}$ with a maximum deviation of $0.079(2) \AA$ for atom $\mathrm{C} 1$ and 0.004(3) $\AA$ for atom C8 (Fig. 1). The N2 $\equiv \mathrm{C} 13$ 1.131(4) $\AA$. and $\mathrm{N} 1 \equiv \mathrm{C} 141.130(3) \AA$. bonds show $\mathrm{N} \equiv \mathrm{C}$ triple bond character and are in good agreement with the literature values. ${ }^{40-43}$ The S1-C1 and S1-C7 bond lengths are slightly different than the accepted value for an $\mathrm{S}-\mathrm{Cs} p^{2}$ single bond $\left(1.76 \AA ;^{44}\right)$, resulting from the conjugation of the electrons of atom S1 with atoms $\mathrm{C} 1$ and $\mathrm{C} 7$.

For the title compound, there is an intermolecular $\mathrm{C}-\mathrm{H} \cdots \mathrm{N}$

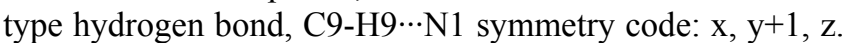
(Table 1). In the crystal packing, the phthalonitrile groups are close to each other with antiparallel manner along the $a$ axis of the unit cell, in the closest interaction with a perpendicular separation of $3.42 \AA$ (Fig. 2).

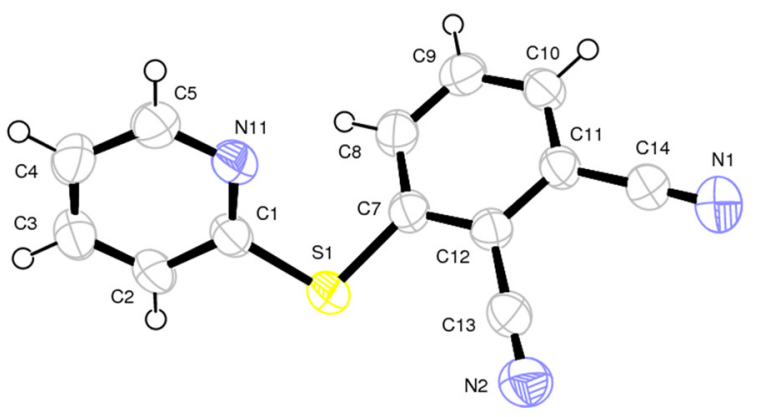

Figure 1. Ortep 3 diagram of the title compound. Displacement ellipsoids are drawn at the $50 \%$ probability level and $\mathrm{H}$ atoms are shown as small spheres of arbitrary radii. 
Table 1. Hydrogen-bond geometry $\left(\AA,{ }^{\circ}\right)$

\begin{tabular}{ccccc}
\hline $\mathrm{D}-\mathrm{H} \cdots \mathrm{A}$ & $\mathrm{D}-\mathrm{H}$ & $\mathrm{H} \cdots \mathrm{A}$ & $\mathrm{D} \cdots \mathrm{A}$ & $\mathrm{D}-\mathrm{H} \cdots \mathrm{A}$ \\
\hline $\begin{array}{c}\mathrm{X}-\mathrm{ray} \\
\mathrm{C} 9-\mathrm{H} 9 \cdots \mathrm{N} 1^{(\mathrm{i})}\end{array}$ & 0.93 & 2.59 & $3.495(5)$ & 163.4 \\
$\begin{array}{c}\mathrm{B} 3 \mathrm{LYP} / 6-31 \mathrm{G}(\mathrm{d}) \\
\mathrm{C} 9-\mathrm{H} 9 \cdots \mathrm{N} 1^{(\mathrm{i})}\end{array}$ & 1.085 & 2.549 & 3.634 & 177.89 \\
$\cdots \cdots$ & & & & \\
$\mathrm{HF} / 6-31 \mathrm{G}(\mathrm{d})$ & & & & \\
$\mathrm{C} 9-\mathrm{H} 9 \cdots \mathrm{N} 1^{(\mathrm{i})}$ & 1.073 & 2.791 & 3.608 & 132.96 \\
\hline
\end{tabular}

Symmetry code: (i) $\mathrm{x}, \mathrm{y}+1, \mathrm{z}$.

Optimized Structures. B3LYP/6-31G(d) and HF/6-31G(d) calculations were performed on the title compound. Calculated geometric parameters are listed in Supplementary Table 3 along with the experimental data. The molecular structure of the title compound is not planar. The dihedral angle between the pyridine and phthalonitrile rings is $62.11(1)^{\circ}$ for X-ray analysis, whereas the dihedral angle has been calculated as $55.79^{\circ}$ for B3LYP and $77.07^{\circ}$ for HF. When the X-ray structure of the title compound is compared with its optimized counterpart (see Fig. 3), conformational discrepancies are observed. The most remarkable discrepancies are found in the orientation of the phthalonitrile ring of the title compound, which is defined by torsion angles C1-S1-C7-C8 -48.1(3) ${ }^{\circ}$ and C2-C1-S1-C7 155.0(2) ${ }^{\circ}$. These torsion angles have been calculated at $-108.1^{\circ}$ and $-169.7^{\circ}$ for the HF/6-31G(d) level, and $-59.9^{\circ}$ and $-172.7^{\circ}$ for the B3LYP/6-31G(d) level. When the geometry of hydrogen bond in the optimized structures is examined, the proton donor group C9-H9 forms an intermolecular interaction with the $\mathrm{N} 1$ atom, with a bond length of $2.791 \AA$ and a bond angle of $132.96^{\circ}$ for

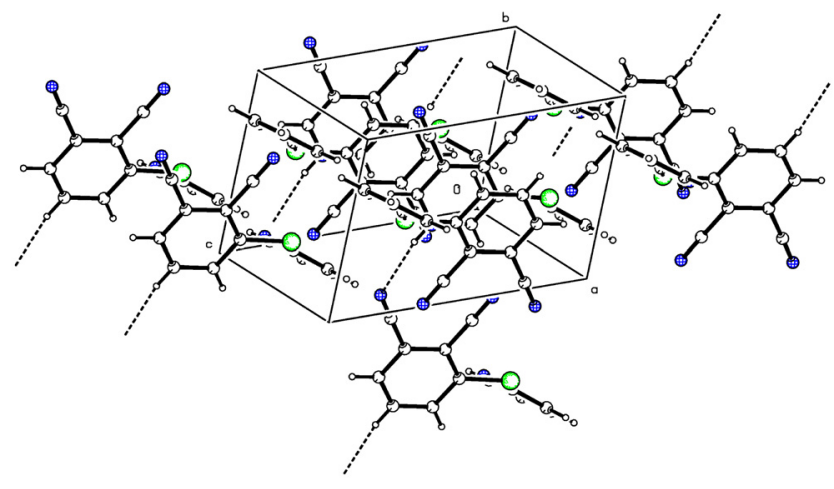

Figure 2. Packing diagram of the title compound.

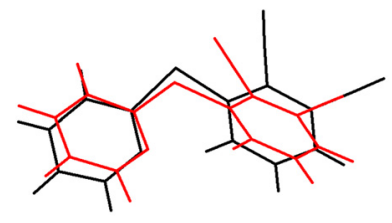

(a)

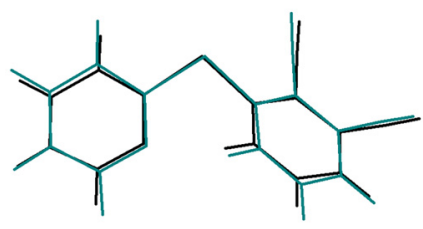

(b)
Figure 3. Atom-by-atom superimposition of the structures calculated $\mathrm{a}=\mathrm{HF}$ (red); b = B3LYP (cyan) over the X-ray structure (black) for the title compound.
Table 2. Total energies and dipole moments of the title compound in different solvent

\begin{tabular}{|c|c|c|c|c|}
\hline Method & Media & $\begin{array}{l}\text { Energy } \\
\text { (a.u.) }\end{array}$ & $\begin{array}{c}\mu \\
\text { (debyes) }\end{array}$ & $\underset{(\mathrm{kJ} / \mathrm{mol})}{\Delta E}$ \\
\hline B3LYP & $\operatorname{Gas}(\varepsilon=1)$ & -1061.999419 & 8.498 & \\
\hline \multirow{3}{*}{ Onsager } & Chloroform $(\varepsilon=4.9)$ & -1062.0072367 & 13.115 & -20.522 \\
\hline & Ethanol $(\varepsilon=24.55)$ & -1062.0111093 & 14.578 & -30.689 \\
\hline & Water $(\varepsilon=78.39)$ & -1062.0119326 & 14.878 & -32.852 \\
\hline \multirow{3}{*}{ PCM } & Chloroform $(\varepsilon=4.9)$ & -1062.0145831 & 10.553 & -39.810 \\
\hline & Ethanol $(\varepsilon=24.55)$ & -1062.0201283 & 11.252 & -54.371 \\
\hline & Water $(\varepsilon=78.39)$ & -1062.0216366 & 11.391 & -58.329 \\
\hline
\end{tabular}

HF and a bond length of $2.549 \AA$ and a bond angle of $177.89^{\circ}$ for B3LYP (Table 1).

In spite of the differences, calculated geometric parameters represent a good approximation, and they are the basis for calculating other parameters, such as vibrational frequencies, electronic absorption spectra and the molecular electrostatic potential, as described below.

Total Energetics and Dipole Moments. In order to evaluate the energetic behavior of the title compound in solvent media, we carried out calculations in three kinds of solvent (chloroform, ethanol, water). Total energies and dipole moments have been calculated in solvent media with B3LYP/6-31G (d) level using Onsager and PCM models and the results are presented in Table 2.

As can be seen from the table, the obtained total energies of the title compound using the Onsager and PCM methods decrease with increasing polarity of the solvent. The energy difference between gas phase and solvent media was significant for both the methods. According to results, the PCM method provided lower energy than Onsager's method $(22.815 \mathrm{kj} / \mathrm{mol}$ average). In addition, the computed dipole moments of Onsager model are larger than those of PCM model in different solvents, and the dipole moments for two solvation methods grow with the increase of the solvent polarity.

Vibrational Spectra. Harmonic vibrational frequencies of the title compound were calculated using the the DFT/B3LYP and HF methods with the $6-31 \mathrm{G}(\mathrm{d})$ basis set. The vibrational band assignments were made using the Gauss-View molecular visualisation program. In order to facilitate assignment of the observed peaks, we analyzed the vibrational frequencies and compared our calculation for the title compound with the experimental results (Table 3 ).

The FT-IR spectrum of the title compound is shown in Fig. 4. The aromatic structure shows the presence of C-H stretching vibrations in the region $2900-3150 \mathrm{~cm}^{-1}$, which is the characteristic region for the identification of $\mathrm{C}-\mathrm{H}$ stretching vibrations. In this region, the bands are not appreciably affected by the nature of the substituent. ${ }^{45}$ The $\mathrm{C}$-H aromatic stretching mode was observed at $3068.31 \mathrm{~cm}^{-1}$ experimentally, and calculated at $3099.94 \mathrm{~cm}^{-1}$ for B3LYP and at $3041.61 \mathrm{~cm}^{-1}$ for HF. The experimental $\mathrm{C} \equiv \mathrm{N}$ stretching mode was observed at 2234.65 $\mathrm{cm}^{-1}$ which is a strong band, that have been calculated at 2260.14 $\mathrm{cm}^{-1}$ for B3LYP and $2337.38 \mathrm{~cm}^{-1}$ for HF. In the phthalonitrile, 
Table 3. Comparison of the experimental and calculated vibrational frequencies $\left(\mathrm{cm}^{-1}\right)$

\begin{tabular}{|c|c|c|c|}
\hline \multirow{3}{*}{ Assignments $^{a}$} & \multirow{3}{*}{$\begin{array}{l}\text { Experimental } \\
\text { IR with } \mathrm{KBr}\end{array}$} & \multicolumn{2}{|c|}{ Calculated } \\
\hline & & $\mathrm{HF} / 6-31 \mathrm{G}(\mathrm{d})$ & B3LYP/6-31G(d) \\
\hline & & Scaled freq. & Scaled freq. \\
\hline$v \mathrm{C}-\mathrm{H}$ of $\mathrm{R}_{1}$ & 3068.31 & 3041.61 & 3099.94 \\
\hline$v \mathrm{C} \equiv \mathrm{N}$ & 2234.65 & 2337.38 & 2260.14 \\
\hline$v \mathrm{C}=\mathrm{C}$ of $\mathrm{R}_{1}+\nu \mathrm{C}=\mathrm{N}+\gamma \mathrm{C}-\mathrm{H}$ of $\mathrm{R}_{1}$ & 1578.54 & 1600.91 & 1573.19 \\
\hline$v \mathrm{C}=\mathrm{C}$ of $\mathrm{R}_{1}+v \mathrm{C}-\mathrm{N}+\gamma \mathrm{C}-\mathrm{H}$ of $\mathrm{R}_{1}$ & 1451.17 & 1465.8 & 1448.27 \\
\hline$v \mathrm{C}=\mathrm{C}$ of $\mathrm{R}_{1,2}+\gamma \mathrm{C}-\mathrm{H}$ of $\mathrm{R}_{1,2}$ & 1416.44 & 1425.36 & 1408.68 \\
\hline$v \mathrm{C}-\mathrm{N}+\nu \mathrm{C}=\mathrm{C}$ of $\mathrm{R}_{2}+\gamma \mathrm{C}-\mathrm{H}$ of $\mathrm{R}_{1,2}$ & 1285.22 & 1278.07 & 1276.62 \\
\hline$\gamma \mathrm{C}-\mathrm{H}$ of $\mathrm{R}_{1}$ & 1150.13 & 1181.22 & 1142.06 \\
\hline$v \mathrm{C}-\mathrm{S}+\gamma \mathrm{C}-\mathrm{H}$ of $\mathrm{R}_{1}$ & 1111.54 & 1114.25 & 1098.69 \\
\hline$v \mathrm{C}-\mathrm{S}+\gamma \mathrm{C}-\mathrm{H}$ of $\mathrm{R}_{1}$ & 1084.52 & 1078.82 & 1073.42 \\
\hline$\theta$ of $\mathrm{R}_{1}$ & 1045.93 & 1023.89 & 1030.23 \\
\hline$\delta \mathrm{C}-\mathrm{H}$ of $\mathrm{R}_{2}+$ Trigonal bending of $\mathrm{R}_{1}$ & 988.03 & 971.29 & 964.77 \\
\hline$v \mathrm{C}-\mathrm{S}+\beta_{\text {deformation }}$ of $\mathrm{R}_{2}+\gamma \mathrm{C}-\mathrm{H}$ of $\mathrm{R}_{2}$ & 810.50 & 832.23 & 830.80 \\
\hline$\omega \mathrm{C}-\mathrm{H}$ of $\mathrm{R}_{1}$ & 756.46 & 765.65 & 744.16 \\
\hline$v \mathrm{C}-\mathrm{S}+\beta_{\text {deformation }}$ of $\mathrm{R}_{1}+\gamma \mathrm{C}-\mathrm{H}$ of $\mathrm{R}_{1}$ & 717.81 & 709.26 & 702.58 \\
\hline$\beta_{\text {deformation }}$ of $\mathrm{R}_{1}+\beta \mathrm{CCN}$ of $\mathrm{R}_{2}$ & 617.52 & 606.86 & 605.00 \\
\hline
\end{tabular}

${ }^{a} v$, stretching; $\gamma$, rocking; $\omega$, wagging; $\delta$, twisting; $\theta$, ring breathing; $\beta$, in-plane bending. Abbreviations: $\mathrm{R}_{1}$, pyridine ring; $\mathrm{R}_{2}$, phthalonitrile ring.

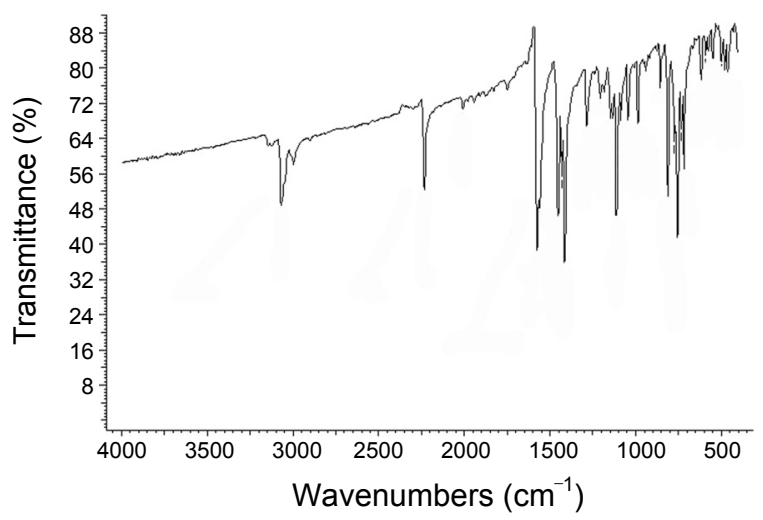

Figure 4. FT-IR spectrum of the title compound.

the $\mathrm{C} \equiv \mathrm{N}$ stretching modes were observed to be 2232 - 2237 $\mathrm{cm}^{-146}$ and $2230 \mathrm{~cm}^{-143}$ as experimentally. These results indicated some band shifts with regard to the different substituentphthalonitrile ring. The benzene ring modes predominantly involve $\mathrm{C}=\mathrm{C}$ bonds and the vibrational frequency is associated with $\mathrm{C}=\mathrm{C}$ stretching modes of carbon skeleton. ${ }^{47}$ The $\mathrm{C}=\mathrm{C}$ stretching modes predicted at $1276.62-1600.91 \mathrm{~cm}^{-1}$ are in a good agreement with the experimental values at 1285.22 $1578.54 \mathrm{~cm}^{-1}$. The stretching $\mathrm{C}=\mathrm{N}$ vibration gives rise a band in the infrared experimental spectrum at $1578.54 \mathrm{~cm}^{-1}$, while the calculated value for HF is predicted $22.37 \mathrm{~cm}^{-1}$ higher, at $1600.91 \mathrm{~cm}^{-1}$ and for B3LYP is predicted $5.35 \mathrm{~cm}^{-1}$ lower, at $1573.19 \mathrm{~cm}^{-1}$. The identification of $\mathrm{C}-\mathrm{N}$ vibrations is a very difficult task, since the mixing of several bands are possible in this region. ${ }^{48}$ Silverstein et al. ${ }^{49}$ assigned C-N stretching absorption in the region $1266-1382 \mathrm{~cm}^{-1}$ for aromatic amines. In benzamide the band observed at $1368 \mathrm{~cm}^{-1}$ is assigned to $\mathrm{C}-\mathrm{N}$ stretching. ${ }^{50}$ In $4-N, N$-dimethylamino pyridine, the $\mathrm{C}-\mathrm{N}$ stretching mode was observed at $1345 \mathrm{~cm}^{-1}$. 48 In our present work, the experimental C-N stretch bands were observed at 1451.17 -

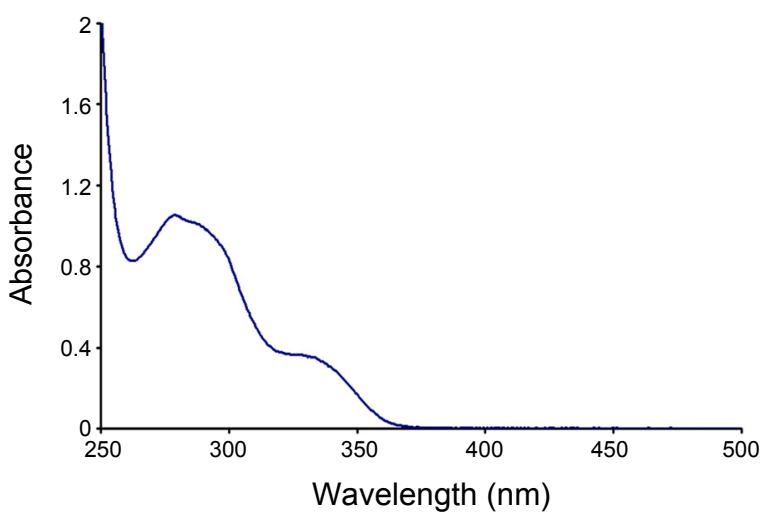

Figure 5. UV-vis spectrum of the title compound.

$1285.22 \mathrm{~cm}^{-1}$, that have been calculated at $1448.27-1276.62$ $\mathrm{cm}^{-1}$ for B3LYP and $1465.8-1278.07 \mathrm{~cm}^{-1}$ for HF, respectively. Like C-N vibrations its also difficult to assign the band due to $\mathrm{C}-\mathrm{S}$ stretching vibrations because the band is of variable intensity and can be found over the wide region $1250-250 \mathrm{~cm}^{-1}$. The C-S group is less polar than carbonyl links and has a considerably weaker band. In consequence, the bond is not intense, and it falls at lower frequencies. Identification is therefore difficult and uncertain. ${ }^{51}$ The experimental vibrational bands for the C-S stretching vibrations are located at 1111.54, 1084.52, 810.50 and $717.81 \mathrm{~cm}^{-1}$ with corresponding calculated values at $1098.69,1073.42,830.80$ and $702.58 \mathrm{~cm}^{-1}$ for B3LYP and $1114.25,1078.82,810.50$ and $717.81 \mathrm{~cm}^{-1}$ for HF. These bands are in good agreement with the literature values. ${ }^{52-54}$ The other calculated vibrational frequencies can be seen in Table 5 .

Electronic Absorption Spectra. The electronic absorption spectra of the title compound in chloroform solvent were recorded within the $200-600 \mathrm{~nm}$ range and representative spectrum is shown in Fig. 5. As can be seen from the figure, electronic absorption spectra of the title compound show two bands 


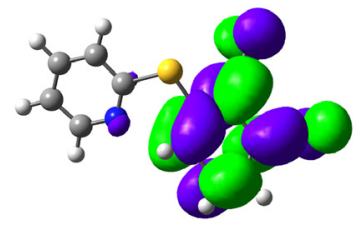

LUMO (-2.198 eV)

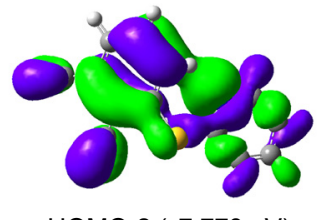

HOMO-2 (-7.778 eV)

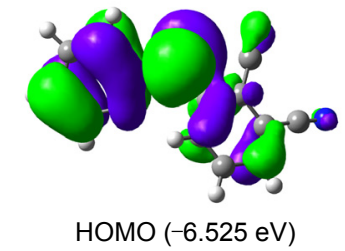

Figure 6. Molecular orbital surfaces and energy levels given in parantheses for the HOMO-2, HOMO and LUMO of the title compound computed at B3LYP/6-31G(d) level.

at $280 \mathrm{~nm}$ with $\log \varepsilon=3.989$ and $335 \mathrm{~nm}$ with $\log \varepsilon=3.519$. Electronic absorption spectra of the title compound were calculated using the TD-DFT and TD-HF methods based on the B3LYP/6-31G(d) and HF/6-31G(d) level optimized structure in gas phase, respectively. For the TD-HF calculations, the absorption wavelengths are obtained at 190 and $231 \mathrm{~nm}$. It is obvious that these bands are not corresponding to the experimental results, which shows that to use TD-HF method here to predict the electronic absorption spectra is not reasonable. For TD-DFT calculations, the theoretical absorption bands are predicted at 239 and $340 \mathrm{~nm}$ and can easily be seen that they correspond to the experimental absorption ones. In addition to the calculations in gas phase, TD-DFT calculations of the title compound in chloroform solvent were performed using the PCM model. The PCM calculations reveal that the calculated absorption bands have slight red-shift with values of 244 and $353 \mathrm{~nm}$ when comparing with the gas phase calculations of TD-DFT method.

According to the investigation on the frontier molecular orbital (FMO) energy levels of the title compound, we can find that the corresponding electronic transfers happened between the highest occupied molecular orbital (HOMO) and the lowest unoccupied molecular orbital (LUMO), HOMO-2 and LUMO orbitals, respectively. Fig. 6 shows the distributions and energy levels of the HOMO-2, HOMO and LUMO orbitals computed at the B3LYP/6-31G(d) level for the title compound. As can be seen from the figure, in the HOMO, electrons are mainly delocalized on the pyridine ring and the $\mathrm{S}$ atom as well as nitrogen atoms of cyano groups; in the LUMO the electrons are delocalized on the phthalonitrile fragment and in the HOMO-2, the electrons are delocalised on the whole structure. Molecular orbital coefficients analyses based on B3LYP76-31G(d) optimized geometry indicated that, for the title compound, the FMOs are mainly composed of p-atomic orbitals, so aforementioned electronic transitions are mainly derived from the contribution of band $\pi \rightarrow \pi^{*}$.

Molecular Electrostatic Potential. The MEP is related to the electronic density and is a very useful descriptor in determining the sites for electrophilic and nucleophilic reactions as well as

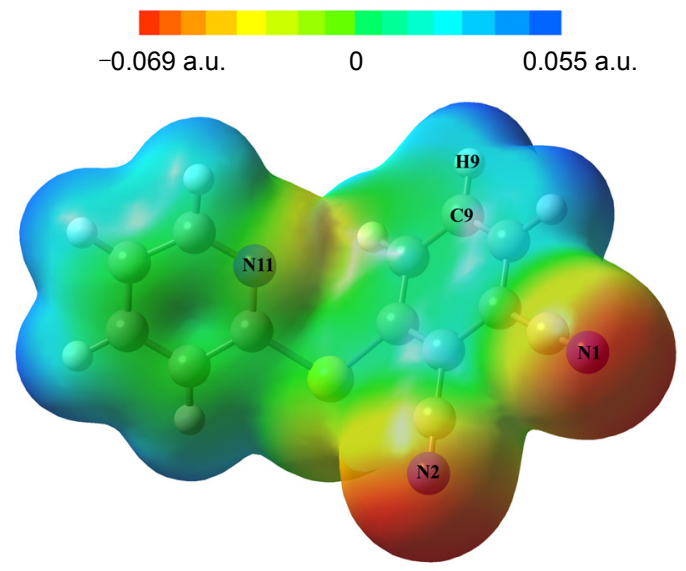

Figure 7. Molecular electrostatic potential map calculated at B3LYP/ 6-31G(d) level.

hydrogen bonding interactions. ${ }^{55,56}$ The electrostatic potential $V(r)$ is also well suited for analysing processes based on the 'recognition' of one molecule by another, as in drug-receptor and enzyme-substrate interactions, because it is through their potentials that the two species first "see" each other. ${ }^{57,58}$ Being a real physical property, $V(r)$ can be determined experimentally by diffraction or by computational methods. ${ }^{59}$

To predict reactive sites for electrophilic and nucleophilic attack for the investigated molecule, the MEP at the B3LYP/ 6-31G(d) optimized geometry was calculated. The negative (red and yellow) regions of the MEP are related to electrophilic reactivity and the positive (blue) regions to nucleophilic reactivity, as shown in Fig. 7. As can be seen from the figure, this molecule has two possible sites for electrophilic attack. Negative regions are mainly localized over the $\mathrm{N} 1$ and N2 atoms of the cyano groups. Also, a negative electrostatic potential region is observed around the $\mathrm{N} 11$ atom. The negative $V(r)$ values are -0.069 a.u. for the $\mathrm{N} 1$ atom, which is the most negative region, -0.067 a.u. for $\mathrm{N} 2$ and -0.037 a.u. for N11, which is the least negative region. However, a maximum positive region is localized on the $\mathrm{C} 9$-H9 bond with a value of +0.055 a.u., indicating a possible site for nucleophilic attack.

According to these calculated results, the MEP map shows that the negative potential sites are on electronegative $\mathrm{N}$ atoms as well as the positive potential sites are around the hydrogen atoms. These sites give information about the region from where the compound can have intermolecular interactions. So, Fig. 7 confirms the existence of an intermolecular C9-H9 $\cdots \mathrm{N} 1$ interaction.

Nonlinear Optical Effects. NLO effects arise from the interactions of electromagnetic fields in various media to produce new fields altered in phase, frequency, amplitude or other propagation characteristics from the incident fields. ${ }^{60}$ NLO is at the forefront of current research because of its importance in providing the key functions of frequency shifting, optical modulation, optical switching, optical logic, and optical memory for the emerging technologies in areas such as telecommunications, signal processing, and optical interconnections. ${ }^{61-64}$ 
The non-linear optical response of an isolated molecule in an electric field $E_{i}(\omega)$ can be presented as a Taylor series expansion of the total dipole moment, $\mu_{t o t}$, induced by the field:

$$
\mu_{t o t}=\mu_{0}+\alpha_{i j} E_{j}+\beta_{i j k} E_{j} E_{k}+\ldots,
$$

where $\alpha$ is the linear polarizability, $\mu_{0}$ the permanent dipole moment and $\beta_{i j k}$ are the first hyperpolarizability tensor components. The isotropic (or average) linear polarizability is defined as: ${ }^{65}$

$$
\alpha_{t o t}=\frac{\alpha_{x x}+\alpha_{y y}+\alpha_{z z}}{3}
$$

First hyperpolarizability is a third rank tensor that can be described by $3 \times 3 \times 3$ matrix. The 27 components of $3 \mathrm{D}$ matrix can be reduced to 10 components due to the Kleinman symmetry $^{66}\left(\beta_{x y y}=\beta_{y x y}=\beta_{y y x}=\beta_{y y z}=\beta_{y z y}=\beta_{z y y} ; \ldots\right.$ likewise other permutations also take same value). The output from Gaussian 03 provides 10 components of this matrix as $\beta_{x x x}, \beta_{x x y}$, $\beta_{x y y}, \beta_{y y y}, \beta_{x x z}, \beta_{x y z}, \beta_{y y z}, \beta_{x z z}, \beta_{y z z}, \beta_{z z z}$, respectively. The components of the first hyperpolarizability can be calculated using the following equation: ${ }^{65}$

$$
\beta_{i}=\beta_{i i i}+\frac{1}{3} \sum_{i \neq j}\left(\beta_{i j j}+\beta_{j i j}+\beta_{j j i}\right)
$$

Using the $\mathrm{x}, \mathrm{y}$ and $\mathrm{z}$ components of $\beta$, the magnitude of the first hyperpolarizability tensor can be calculated by:

$$
\beta_{t o t}=\sqrt{\left(\beta_{x}^{2}+\beta_{y}^{2}+\beta_{z}^{2}\right)}
$$

The complete equation for calculating the magnitude of $\beta$ from Gaussian 03W output is given as follows:

$$
\beta_{t o t}=\sqrt{\left(\beta_{x x x}+\beta_{x y y}+\beta_{x z z}\right)^{2}+\left(\beta_{y y y}+\beta_{y z z}+\beta_{y x x}\right)^{2}+\left(\beta_{z z z}+\beta_{z x x}+\beta_{z y y}\right)^{2}}
$$

The calculations of the total molecular dipole moment $(\mu)$, linear polarizability $(\alpha)$ and first-order hyperpolarizability $(\beta)$ from the Gaussian output have been explained in detail previously, ${ }^{67}$ and DFT has been extensively used as an effective method to investigate the organic NLO materials. ${ }^{68-72}$ In addition, the polar properties of the title compound were calculated at the B3LYP/6-31G(d) level using Gaussian 03W program package.

Urea is one of the prototypical molecules used in the study of the NLO properties of molecular systems. Therefore it was used frequently as a threshold value for comparative purposes. The calculated values of $\alpha$ and $\beta$ for the title compound are $25.005 \AA^{3}$ and $2.8227 \times 10^{-30} \mathrm{~cm}^{5} / \mathrm{esu}$, which are greater than those of urea (the $\alpha$ and $\beta$ of urea are $3.8312 \AA^{3}$ and $3.7289 \times$ $10^{-31} \mathrm{~cm}^{5} /$ esu obtained by B3LYP/6-31G(d) method). Theoretically, the first hyperpolarizability of the title compound is of 7.57 times magnitute of urea. According to the magnitude of
Table 4. Thermodynamic properties at different temperatures at B3LYP/6-31G(d) level

\begin{tabular}{cccc}
\hline $\mathrm{T}(\mathrm{K})$ & $H_{m}^{0}\left({\left.\mathrm{kcal} . \mathrm{mol}^{-1}\right)}^{C_{p, m}^{0}}\left({\left.\mathrm{cal} . \mathrm{mol}^{-1} \cdot \mathrm{K}^{-1}\right)} S_{m}^{0}\left(\mathrm{cal} . m o l^{-1} \cdot \mathrm{K}^{-1}\right)\right.\right.$ \\
\hline $\mathbf{2 0 0}$ & 5.01 & 39.20 & 107.41 \\
$\mathbf{2 5 0}$ & 7.28 & 47.35 & 117.48 \\
$\mathbf{2 9 8 . 1 5}$ & 9.84 & 54.92 & 126.83 \\
$\mathbf{3 0 0}$ & 9.94 & 55.20 & 127.18 \\
$\mathbf{3 5 0}$ & 12.99 & 62.52 & 136.55 \\
$\mathbf{4 0 0}$ & 16.38 & 69.18 & 145.61 \\
\hline
\end{tabular}

the first hyperpolarizability, the title compound may be a potential applicant in the development of NLO materials.

Thermodynamic Properties. On the basis of vibrational analysis and statistical thermodynamics, the standard thermodynamic functions: heat capacity $\left(C_{p, m}^{0}\right)$, entropy $\left(S_{m}^{0}\right)$, and enthalpy $\left(H_{m}^{0}\right)$ were obtained at B3LYP/6-31G(d) level and listed in Table 4. Table 4 shows that the standard heat capacities, entropies, and enthalpies increase at any temperature from 200.00 to $400.00 \mathrm{~K}$, because the intensities of molecular vibration increase with the increasing temperature.

The correlation equations between these thermodynamic properties and temperature $T$ are as follows:

$$
\begin{aligned}
H_{m}^{0}=- & 0.36511+0.01183 T+7.51151 \times 10^{-5} T^{2}, \\
& \left(\mathrm{R}^{2}=0.99999\right) \\
C_{p, m}^{0}= & 1.06621+0.21059 T-1.00551 \times 10^{-4} T^{2}, \\
& \left(\mathrm{R}^{2}=0.99996\right) \\
S_{m}^{0}= & 63.85139+0.23127 T-6.72103 \times 10^{-5} T^{2},\left(\mathrm{R}^{2}=1\right)
\end{aligned}
$$

These equations will be helpful for the further studies of the title compound.

\section{Conclusions}

3-(2-Mercaptopyridine)phthalonitrile has been synthesized and characterized by IR, UV-vis and X-ray single-crystal diffraction. The $\mathrm{X}$-ray structure is found to be slightly different from its optimised counterparts, and the crystal structure is stabilised by a $\mathrm{C}-\mathrm{H} \cdots \mathrm{N}$ type hydrogen bond. Despite the differences, the general agreement is good and the theoretical calculations support the solid state structures. For the calculation of vibrational frequencies, both the methods, B3LYP and HF, can predict the IR spectrum of title compound well. The TD-DFT calculations lead to much closer agreement with the experimental absorption spectra, both in the gas phase and in solvent media. Molecular orbital coefficient analyses suggest that the electronic spectrum corresponds to the $\pi \rightarrow \pi^{*}$ electronic transition. The MEP map shows that the negative potential sites are on electronegative atoms while the positive potential sites are around the hydrogen atoms. These sites give information about the region from where the compound can undergo intermolecular interactions. The predicted NLO properties of the title compound are much greater than those of urea. The title compound is a good candidate as a second-order nonlinear optical material. The 
correlations between the thermodynamic properties $C_{p, m}^{0}, S_{m}^{0}$, $H_{m}^{0}$ and temperature T were also obtained. We hope our paper will be helpful for the design and synthesis of new materials.

Supporting Information. The supplementary Table 1 and 3 are available via the Internet, http://newjournal. kcsnet.or.kr. CCDC 677705 contains the supplementary crystallographic data (excluding structure factors) for the structure reported in this article. These data can be obtained free of charge at www.ccdc. cam.ac.uk/conts/retrieving.html [or from the Cambridge Crystallographic Data Centre (CCDC), 12 Union Road, Cambridge CB2 1EZ, UK; fax: +44(0)1222-336033; email: deposit@ccdc. cam.ac.uk].

\section{References}

1. Oae, I. S. Organic Sulfur Chemistry: Structure and Mechanism; CRC Press Inc.: Florida, 1992.

2. Millar, A.; Krebs, B. Sulfur, Its Significance for Chemistry, for Geology Biology, Cosmo Sphere and Technology; Elsevier: Amsterdam, 1989.

3. Lobana, T. S.; Sharma, R.; Butcher, R. J. Polyhedron 2008, 27, 1375.

4. Lee, F. Y.; Huang, J. J.; Chen, Y. J.; Lin, K. J.; Lee, G. H.; Peng, S. M.; Hwu, J. R.; Lu, K. L. J. Organometallic Chem. 2005, 690, 441.

5. Lobana, T. S.; Kaur, P.; Castineiras, A.; Turner, P.; Failes, T. W. Struct. Chem. 2008, 19, 727.

6. Leznoff, C. C., Lever, A. B. P., Eds.; Phthalocyanines: Properties and Applications; VCH: New York, 1989; 1993; 1996; Vols. 1-4.

7. Kadish, K. M.; Smith, K. M.; Guilard, R. The Porphyrin Handbook; Academic Press: California, 2003; Vols. 15-20.

8. Halls, M. D.; Aroca, R.; Terekhov, D. S.; D'Ascanio, A.; Leznoff, C. C. Spectrochim. Acta Part A 1998, 54, 305.

9. Prasad, P. N.; Williams, D. J. Introduction to Nonlinear Optical Effects in Molecules and Polymers; Wiley: New York, 1991.

10. Kanis, D. R.; Ratner, M. A.; Marks, T. J. Chem. Rev. 1994, 94 , 195.

11. Avcı, D.; Başoğlu, A.; Atalay, Y. Struct. Chem. doi:10.1007/ s11224-009-9566-1.

12. Matulkova, I.; Nemec, I.; Teubner, K.; Nemec, P.; Micka, Z. J. Mol. Struct. 2008, 873, 46.

13. Boo, B. H.; Lee, J. K.; Lim, E. C. J. Mol. Struct. 2008, 892, 110.

14. Proft, F. D.; Geerlings, P. Chem. Rev. 2001, 101, 1451.

15. Tanak, H.; Erşahin, F.; Köysal, Y.; Ağar, E.; Iş1k, Ş.; Yavuz, M. J. Mol. Mod. 2009, 15, 1281.

16. Kurt, M.; Sertbakan, T. R.; Ozduran, M. Spectrochim. Acta Part A 2008, 70, 664 .

17. Jian, F. F.; Zhao, P. S.; Bai, Z. S.; Zhang, L. Struct. Chem. 2005, $16,635$.

18. Sun, Y.-X.; Hao, Q.-L.; Wei, W.-X.; Yu, Z.-X.; Lu, L.-D.; Wang, X. J. Mol. Struct. THEOCHEM 2009, 904, 74.

19. Sun, Y.-X.; Hao, Q.-L.; Yu, Z.-X.; Wei, W.-X.; Lu, L.-D.; Wang, X. Mol. Phys. 2009, 107, 223.

20. Sehlotho, N.; Durmuş, M.; Ahsen, V.; Nyokong, T. Inorg. Chem. Commun. 2008, 1, 1479.

21. Stoe \& Cie, X-AREA Version 1.18 and X-RED32 Version 1.04, Stoe \& Cie, Darmstadt, Germany, 2002.

22. Sheldrick, G. M. SHELXS97 and SHELXL97; University of Göttingen: Germany, 1997.

23. Farrugia, L. J. J. Appl. Crystallogr. 1997, 30, 565.

24. Farrugia, L. J. J. Appl. Crystallogr. 1999, 32, 837.

25. Nardelli, M. J. Appl. Crystallogr. 1995, 28, 659.

26. Schlegel, H. B. J. Comput. Chem. 1982, 3, 214.

27. Peng, C.; Ayala, P. Y.; Schlegel, H. B.; Frisch, M. J. J. Comput.
Chem. 1996, 17, 49.

28. Frisch, M. J.; Trucks, G. W.; Schlegel, H. B.; Scuseria, G. E.; Robb, M. A.; Cheeseman, J. R.; Montgomery, J. A.; Vreven, T., Jr.; Kudin, K. N.; Burant, J. C.; Millam, J. M.; Iyengar, S. S.; Tomasi, J.; Barone, V.; Mennucci, B.; Cossi, M.; Scalmani, G.; Rega, N.; Petersson, G. A.; Nakatsuji, H.; Hada, M.; Ehara, M.; Toyota, K.; Fukuda, R.; Hasegawa, J.; Ishida, M.; Nakajima, T.; Honda, Y.; Kitao, O.; Nakai, H.; Klene, M.; Li, X.; Knox, J. E.; Hratchian, H. P.; Cross, J. B.; Adamo, C.; Jaramillo, J.; Gomperts, R.; Stratmann, R. E.; Yazyev, O.; Austin, A. J.; Cammi, R.; Pomelli, C.; Ochterski, J. W.; Ayala, P. Y.; Morokuma, K.; Voth, G. A.; Salvador, P.; Dannenberg, J. J.; Zakrzewski, V. G.; Dapprich, S.; Daniels, A. D.; Strain, M. C.; Farkas, O.; Malick, D. K.; Rabuck, A. D.; Raghavachari, K.; Foresman, J. B.; Ortiz, J. V.; Cui, Q.; Baboul, A. G.; Clifford, S.; Cioslowski, J.; Stefanov, B. B.; Liu, G.; Liashenko, A.; Piskorz, P.; Komaromi, I.; Martin, R. L.; Fox, D. J.; Keith, T.; Al-Laham, M. A.; Peng, C. Y.; Nanayakkara, A.; Challacombe, M.; Gill, P. M. W.; Johnson, B.; Chen, W.; Wong, M. W.; Gonzalez, C.; Pople, J. A. Gaussian, Inc.: Wallingford, CT, 2004.

29. Foresman, J. B.; Frisch, A. Exploring Chemistry with Electronic Structure Methods; Gaussian Inc.: Pittsburgh, 1996.

30. Dennington, R., II.; Keith, T.; Millam, J. GaussView, Version 4.1.2, Semichem, Inc., Shawnee Mission, KS, 2007.

31. Runge, E.; Gross, E. K. U. Phys. Rev. Lett. 1984, 52, 997.

32. Stratmann, R. E.; Scuseria, G. E.; Frisch, M. J. J. Chem. Phys. 1998, $109,8218$.

33. Bauernschmitt, R.; Ahlrichs, R. Chem. Phys. Lett. 1996, 256, 454.

34. Casida, M. E.; Jamorski, C.; Casida, K. C.; Salahub, D. R. J. Chem. Phys. 1998, 108, 4439.

35. Miertus, S.; Scrocco, E.; Tomasi, J. Chem. Phys. 1981, 55, 117.

36. Barone, V.; Cossi, M. J. Phys. Chem. A 1998, 102, 1995.

37. Tomasi, J.; Mennucci, B.; Cammi, R. Chem. Rev. 2005, 105, 2999.

38. Onsager, L. J. Am. Chem. Soc. 1936, 58, 1486.

39. Politzer, P.; Murray, J. S. Theor. Chem. Acc. 2002, 108, 134

40. Iskeleli, N. O. Acta Cryst. E 2007, 63, 997.

41. Işı1, Ş.; Köysal, Y. Acta Cryst. E 2006, 62, 671.

42. Dinçer, M.; Agar, A.; Akdemir, N.; Ağar, E.; Özdemir, N. Acta Cryst. E 2004, 60, 79.

43. Zhang, X.-F.; Jia, D.; Songa, A.; Liu, Q. Acta Cryst. E 2008, 64, 356.

44. Allen, F. H. Acta Cryst. B 1984, 40, 64.

45. Teimouri, A.; Emami, M.; Chermahini, A. N.; Dabbagh, H. A. Spectrochim. Acta Part A 2009, 71, 1749.

46. Halls, M. D.; Aroca, R.; Terekhov, D. S.; D'Ascanio, A.; Leznoff, C. C. Spectrochim. Acta Part A 1998, 54, 305.

47. Teimouri, A.; Chermahini, A. N.; Taban, K.; Dabbagh, H. A. Spectrochim. Acta Part A 2009, 72, 369.

48. Sundaraganesan, N.; Kalaichelvan, S.; Meganathan, C.; Dominic Joshua, B.; Cornard, J. Spectrochim. Acta Part A 2008, 71, 898.

49. Silverstein, M.; Clayton Basseler, G.; Moril, C. Spectrometric Identification of Organic Compounds; Wiley: New York, 1981.

50. Shunmugam, R.; Sathyanarayana, D. Spectrochim. Acta Part A 1984, 40, 757.

51. Krishnakumar, V.; John Xavier, R. Spectrochim. Acta Part A 2006, 63,454 .

52. Tuttolomondo, M. E.; Navarro, A.; Ruiz, T. P.; Varetti, E. L.; Hayes, S. A.; Wann, D. A.; Robertson, H. E.; Rankin, D. W. H.; Altabef, A. B. J. Phys. Chem. A 2007, 111, 9952.

53. Mohamed, G. G. Spectrochim. Acta Part A 2001, 57, 411.

54. Xiao-Hong, L.; Zheng-Xin, T.; Xian-Zhou, Z. Spectrochim. Acta Part $A$ 2009, 74, 168.

55. Scrocco, E.; Tomasi, J. Adv. Quantum. Chem. 1979, 11, 115.

56. Luque, F. J.; Lopez, J. M.; Orozco, M. Theor. Chem. Acc. 2000, 103, 343.

57. Politzer, P.; Laurence, P. R.; Jayasuriya, K.; McKinney, J. Environ. Health Perspect. 1985, 61, 191.

58. Scrocco, E.; Tomasi, J. Topics in Current Chemistry; Springer: Berlin, 1973; Vol. 7, p 95. 
59. Politzer, P.; Truhlar, D. G. Chemical Applications of Atomic and Molecular Electrostatic Potentials; Plenum: New York, 1981.

60. Sun, Y. X.; Hao, Q. L.; Wei, W. X.; Yu, Z. X.; Lu, L. D.; Wang, X.; Wang, Y. S. J. Mol. Struct.: THEOCHEM 2009, 904, 74.

61. Andraud, C.; Brotin, T.; Garcia, C.; Pelle, F.; Goldner, P.; Bigot, B.; Collet, A. J. Am. Chem. Soc. 1994, 116, 2094.

62. Geskin, V. M.; Lambert, C.; Bredas, J. L. J. Am. Chem. Soc. 2003, $125,15651$.

63. Nakano, M.; Fujita, H.; Takahata, M.; Yamaguchi, K. J. Am. Chem. Soc. 2002, 124, 9648 .

64. Sajan, D.; Joe, H.; Jayakumar, V. S.; Zaleski, J. J. Mol. Struct. 2006, 785, 43 .

65. Zhang, R.; Du, B.; Sun, G.; Sun, Y. X. Spectrochim. Acta Part A
2010, 75, 1115 .

66. Kleinman, D. A. Phys. Rev. 1962, 126, 1977.

67. Thanthiriwatte, K. S.; Nalin de Silva, K. M. J. Mol. Struct.: THEOCHEM 2002, 617, 169.

68. Sun, Y. X.; Hao, Q. L.; Yu, Z. X.; Wei, W. X.; Lu, L. D.; Wang, X. Mol. Phys. 2009, 107, 223.

69. Ahmed, A. B.; Feki, H.; Abid, Y.; Boughzala, H.; Minot, C.; Mlayah, A. J. Mol. Struct. 2009, 920, 1.

70. Abraham, J. P.; Sajan, D.; Shettigar, V.; Dharmaprakash, S. M.; Nemec, I.; Joe, I. H.; Jayakumar, V. S. J. Mol. Struct. 2009, 917, 27. 71. Sagdinc, S. G.; Esme, A. Spectrochim. Acta Part A 2010, 75, 1370.

72. Ahmed, A. B.; Feki, H.; Abid, Y.; Boughzala, H.; Minot, C. Spectrochim. Acta Part A 2010, 75, 293. 